\title{
David Oliver: A manifesto for multimorbidity
}

\author{
David Oliver consultant in geriatrics and acute general medicine
}

Berkshire

In 2012 a Scottish study of over three million people showed that living with three or more long term medical conditions was the norm for people over $65 .{ }^{1}$ In 2016 a study that used data from more than 200000 people in England aged over 75 showed that $7 \%$ had severe frailty and $21 \%$ moderate frailty. ${ }^{2}$ This year, researchers predicted that the proportion of people in the UK with four or more long term conditions would nearly double between 2015 and 2035, from $9.8 \%$ to $17 \%$. $^{3}$ Two thirds of these would also have dementia, depression, or cognitive impairment.

The need for a greater focus on prevention of ill health is something I have argued for recently, not much of it requiring a traditional medical model. ${ }^{4}$ However, for those people who will continue to get sick and continue to require healthcare we need to transform the business of healthcare, and fast. But how? Here are my suggestions.

First, healthcare professionals' training needs to focus far more on coordinated, planned care of individuals. It should be based on patients' overall goals and priorities and on balancing the risks and benefits of treatments, rather than simply on managing single diseases or organ systems. ${ }^{56}$ Though there are pockets of good practice, such approaches are still far from the norm, and practitioners are often not well trained in them. ${ }^{7}$ This training must include an appropriate amount of exposure to primary and community care, geriatrics, mental health, dementia, and care at the end of life.

Second, research priorities, prestige, and funding need to rebalance to reflect this new reality. Research has tended to focus on single conditions of younger or mid life and on high tech, cutting edge interventions, ${ }^{8}$ rather than on pragmatic models of service delivery for people with complex needs. We have often excluded people with multimorbidity, frailty, or dementia, meaning in turn that the evidence base isn't fit for purpose. ${ }^{910}$

Third, we need to embrace and promote skilled medical generalism of the kind found in general practice, geriatrics, and acute internal medicine. ${ }^{11}$

Fourth, we need to focus much more on tackling inappropriate polypharmacy and the benefits of rational "deprescribing."12 13 Let's think about what we are trying to achieve by prescribing for marginal gains, often driven by incentives that focus on single diseases or overspecialisation, and with insufficient consideration of patients' own goals or the downsides of drug-drug or drug-disease interactions.

Finally, we should redesign healthcare delivery to fit the reality of patients' needs now, and over the next 20 years, not an earlier era when life expectancy was shorter and people often died from single conditions.

This surely includes breaking down arbitrary, artificial, and provider centred barriers between what has traditionally counted as primary, secondary, community, and mental health services. The historical distinction between health and social care is especially ripe for reform, as is our failure to provide adequate support for the millions of unpaid carers who support so many people. ${ }^{14}$ Bowman and Meyer described "formative care" approaches-optimising individuals' quality of life reframed by health status and quality of care-which could bring medical and social models closer together. ${ }^{15}$

If we are serious about making any of this happen at scale, as opposed to pockets of excellence, we can't do it without additional resources (targeted to the right places), adequate staff, and enough time and stability to escape immediate service pressures.

Competing interests: See www.bmj.com/about-bmj/freelance-contributors/davidoliver

Provenance and peer review: Commissioned; not externally peer reviewed.

Barnett K, Mercer SW, Norbury M, Watt G, Wyke S, Guthrie B. Epidemiology of multimorbidity and implications for health care, research, and medical education: a cross-sectional study. Lancet 2012;380:37-43. 10.1016/S0140-6736(12)60240-2 22579043

2 Clegg A, Bates C, Young J, etal . Development and validation of an electronic frailty index using routine primary care electronic health record data. Age Ageing 2016;45:353-60. 10.1093/ageing/afw039 26944937

3 Kingston A, Robinson L, Booth H, Knapp M, Jagger C. for the MODEM project. Projections of multi-morbidity in the older population in England to 2035: estimates from the Population Ageing and Care Simulation (PACSim) model. Age Ageing 2018. 10.1093/ageing/af×201.

4 Oliver D. David Oliver: Getting serious about prevention. BMJ 2018;360:k583. 10.1136/bmj.k583 29467152

5 British Geriatrics Society. Fit for frailty, part 1: Consensus best practice guidance for the care of older people living in community and outpatient settings. www.bgs.org.uk/ campaigns/fff/fff_full.pdf.

6 National Voices. National Voices' vision for person centred coordinated care. https://www. nationalvoices.org.uk/sites/default/files/public/national-voices-narrative-leaflet.pdf. 
7 National Voices. Person-centred care in 2017: evidence from service users. https://www. nationalvoices.org.uk/sites/default/files/public/publications/person-centred care in 2017 -national_voices.pdf.

8 Whitty CJM. Harveian Oration 2017: Triumphs and challenges in a world shaped by medicine. Clin Med (Lond) 2017;17:537-44. 10.7861/clinmedicine.17-6-537 29196355 9 Bartlett C, Doyal L, Ebrahim S, et al. The causes and effects of socio-demographic exclusions from clinical trials. Health Technol Assess 2005;9:iii-iv, ix-x, 1-152.

10 Shenoy P. Harugeri A. Elderly patients' participation in clinical trials. Perspect Clin Res 2015;6:184-9. 10.4103/2229-3485.167099 26623388

11 Oliver D. David Oliver: Celebrating the expert generalist. BMJ 2016;354:i3701. 10.1136/bmj.i3701 27381627
12 Duerden M, Avery T, Payne R. Polypharmacy and medicines optimisation: making it safe and sound. King's Fund. https://www.kingsfund.org.uk/sites/default/files/field/field publication_file/polypharmacy-and-medicines-optimisation-kingsfund-nov13.pdf.

13 Dowden A. Deprescribing: reducing inappropriate polypharmacy. Prescriber 2017;28:45-9. http://onlinelibrary.wiley.com/doi/10.1002/psb.1541/pdf10.1002/psb.1541

14 Oliver D. David Oliver: Taking carers for granted. BMJ 2017;357:j1523. 10.1136/bmj.j1523 28377428

15 Bowman C, Meyer J. Formative Care: Defining the purpose and clinical practice of care for the frail. J R Soc Med 2014;107:95-8. 10.1177/0141076813512298 24334912

Published by the BMJ Publishing Group Limited. For permission to use (where not already granted under a licence) please go to http://group.bmj.com/group/rights-licensing/ permissions 